\title{
الهقاصد الشرعية الاقتصادية، والاجتماعية لتوثيق الديون
}

\section{The legitimate economic and social purposes of debt documentation}

\author{
إعداد الباحث/ محمد بن علي بن أحمد المسعودي \\ طالب باحث دكتور اه المغرب، أستاذ بالتعليم نهائي [جامعي] عتيق معهد القاضي الفقيه عبد الله بن سعيد الوجدي، \\ وجدة، المملكة المغربية
}

Email: Masdy99@hotmail.fr

الملخص:

توثيق الديون أصبح ضرورة لضبط التعامل بالدين على مستوى الأفر اد، و المؤسسات المالية، وله مقاصد كثبرة من أهمها:

المقاصد المالية وتتمثل في حفظ المال من الضياع سواء كان مالا عاما، أم خاصا بإثباته في ذمة المدين، و استيفائه عند حلول أجله دون تعثر ، أو مماطلة. بالحجج الكتابية، و الثفاهية وبالضمانات المالية كالر هن، و الكفالة و غير ها من الضمانات المستجدة في مجال المعاملات المالية. المقاصد الاقتصادية: وتتمنل في:

ـ الاقتصاد في الإنفاق : أي التوسط في تحصيل الحاجي، والكمالي من المطعم، والمشرب، و الملبس، فإن التوثيق يضبطه. فحين يعلم المدين أن الدين مضبوط، وأن جز عا من ماله مثنا مرهون سيقتصد في إنفاقه، وسيسلك مسلك

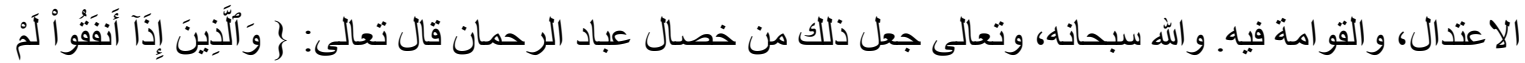

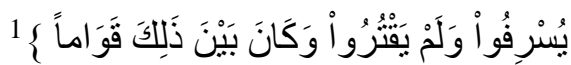
ـ التتمية الاقتصادية : أب تثمير، وتنمية المال بطرق الكسب، و التملك المتعددة بضو ابط الثريعة الإسلامية، وبآدابها المفضيان لاستقامة أحو ال المجتمع، واستقر اره المادي، و الروحي، وهذا بالحصول على التمويلات من قبل المؤسسات، و البنوك التي أخذت الضمانات الكافية من المدين. 
المجلة الدولية لنشر البحوث والدراسات

International Journal of Research and Studies Publishing

المقاصد الاجتماعية: المجتمع المسلم مجتمع متماسك له أسسه، ومقوماته، وقو انينه الضابطة لتصرفات أفر اده، وتوثيق

الديون واحد من تللك المقومات الاجتماعية، وله مقاصد اجتماعية منها: تحقيق العدل، و المساو اة، و الثقة، و المواساة.

وحفظ النفوس. كل هذا يتحقق بتوثيق الدين، وضبطه بقو انين الثرع.

الكلمات المفتّاحية: المقاصد، توثيق، الاقتصـادية، الثروة، العدل، الثقة.

\section{The legitimate economic and social purposes of debt documentation}

\section{Abstract}

Debt registration becomes a necessity to control debt dealing at individual and financial institutions levels. It has many purposes which the means are:

Financial purposes: It consists to save money from losses, whether public or private money, by proving it on debtor's responsibility and paying it at limited time without retardation and procrastination. With written and oral arguments and financial guarantees such mortgage, warranty and other renewed guarantees in financial transaction domains.

The economic purposes, which are:

- To economize expenses: this means to mediate in obtaining the necessary and the perfectionist of food, drinks and cloths, because they are adjusted by the documentation, when the debtor know that the debt is adjusted and that a part of money, for example, is mortgaged, so he will economize in expenses and he will follow the mediation and the stewardship. This is a quality of righteous slaves of Allah, which says:" And [they are] those who, when they spend, do so not excessively or sparingly but are ever, between that, [justly] moderate’’Al-Furqān, verse 67.

- Economic development: investing and developing money by earning methods and multiple ownership in respect to Sharia laws and its ethics which conducts to straightness of society situations and material and spiritual stabilities, all this by obtaining finance from individuals, institutions, and banks that have taken sufficient guarantees from the debtor. 
Social objectives: the Muslim society is coherent and has its foundations, its components and the laws that govern individual behaviors, thus the debt documentation is one of the social components which have many social objectives such achieving justice, equality, confidence, consolation and saving souls. All this can be realized by documenting the debt and controlling it by the laws of Sharia.

Keywords: intent, documentation, economic, wealth, fairness, trust.

الحمد لله رب العالمين، و الصلاة، و السلام على مو لانا رسول الله، و آله وصحبه، ومن و الاه

وبعد: نظر التدفق الإنتاج التكنلوجي، و الاقتصادي بأثكاله، و الإقبال المفرط على استهلاك المنتوجات، والتوسع في تحصيل الحاجيات، و الكماليات، ويقابله محدودية الدخل، أو عدم السيولة أحيانا أصبح التعامل بالدين استهلاكا، وتجارة ظاهرة عالمية.

و الثريعة الإسلامية بأصولها، و أحكامها، ومقاصدها العامة، و الخاصة ضبطت عملية التداين، و أحاطتها بمجموعة من القو انين، و المعايير منها: العقود التوثيقية المصاحبة لكل معاملة مالية، وتعتبر آية توثيق الدين من سورة البقرة أصلا

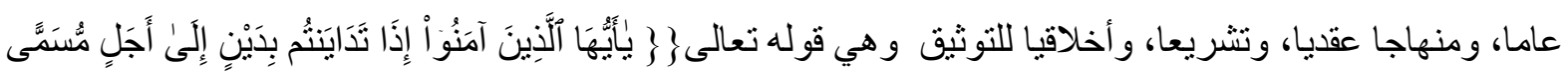

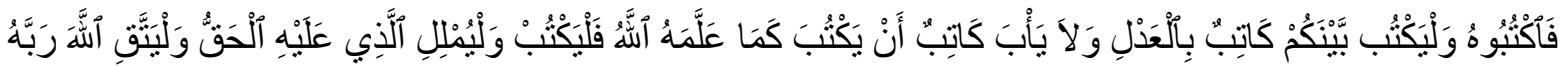

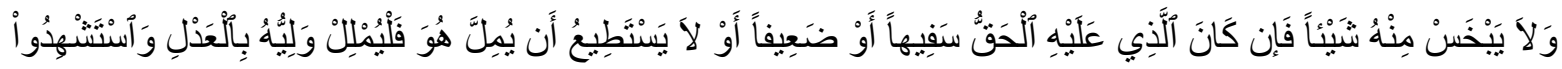

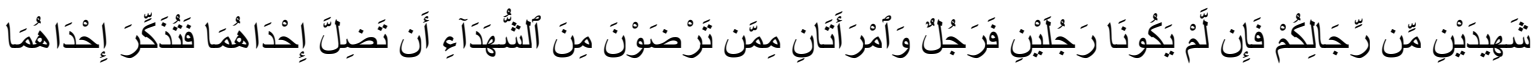

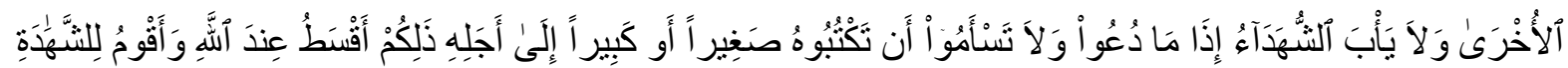

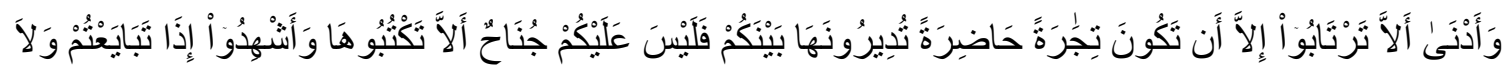

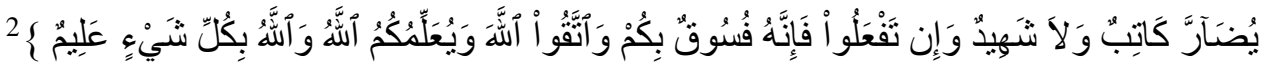
و لأهمية هذا الموضوع، وخطورته تنجز هذه الدراسة بالخطة الآتية: مبحث تمهيدي: في إثنكالية البحث، و أهميته، وأهدافه. وفي معنى توثيق الديون.

$$
\text { المبحث الأول في المقاصد المالبة، والاقتصادية. }
$$


خلاصات، وتوصيات.

المبحث التمهيدي

إشكالية البحث

ليس عيبا ، لا شر عا، و لا عقلا أن يتعامل الناس بالََّّنْ، و أن يكون نو عا من التعامل في التجارة، والسلف، بل هو ضرورة بالنظر لعموم الأمة، وهو حل لكثير من المشاكل، وسبب لتنمية الثروة وهلم جر ا...و واقع الأمة اليوم ينبئ عن كثير من المساوئ الناتجة عن سوء التعامل بالتداين، و عدم الموازنة بين المقدرة الثرائية، و الدخل المالي للفرد، أو الأمة، وعن سوء تدبير الحاجيات، وترتيب الأولويات بسبب الانجر اف من ور اء إغراءات المنتوجات، وتدفقها، و غير ها من الأسباب، و هذا كله أدى إلى ضياع الحقوق المالية، وتعثر أدائها في مو عدها و أدى إلى إفلاس شركات،

و أسر ، و أدى إلى اختلال في القيم الروحية، و الاجتماعية، و أدى إلى أمر اض نفسية. فهل يمكن لتوثيق الديون في الشريعة الإسلامية بما يحمله من دلالات عقدية، وروحية، و اقتصادية، واجتماعية، وقانونية أن يكون ضابطا لعملية التية

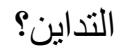

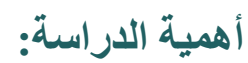
تتجلى أهمية هذه الدر اسة في تحقيق ضبط المدايانات بقو انين الثرع، و آدابه ونوجيهاته لتجنيب المجتمعات آفات سوء تدبير التداين، ومخاطره النفسية، و المالية، و الاجتماعية، و الأخلاقية.

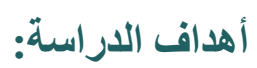

تتوخى هذه الدر اسة تحقيق مجمو عة من الأهداف منها: 1. التحسيس، و إثارة الوعي، وتنكيل العقل لإدر اك ضو ابط التداين، و آدابه. 2. التتبيه على مقاصد توثيق الديون في الثريعة الإسلامية المالية، والاقتصادية، و الاحتماعية. 3. التحذير من مغبة الإفر اط في التداين، وبيان عو اقبه النفسية، والاجتماعية، و الاقتصادية 4. الإسهام في إحياء القيم الفاضلة من عدل، ومواساة، وثنة، وأخوة. مفهوم توثيق الايون هذا المركب الإضافي يحتاج للبيان. أو لا: معنى التوثيق لغة، و اصطلاحا 


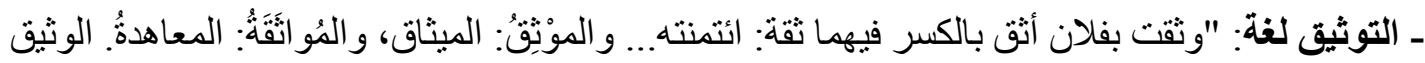

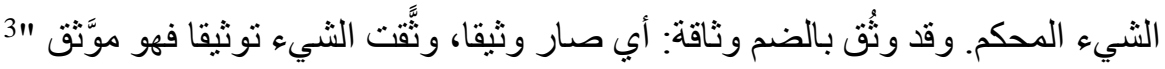

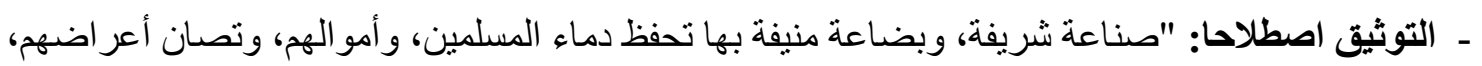

$$
\begin{aligned}
& \text { و أنسابهم" } 4 \\
& \text { ثانيا: معنى الدَّيْن لغة، و اصطلاحا. }
\end{aligned}
$$

- الدين لغة: يقال: "'دنت الرجل: أخذت منه دينا، و أدنته: جعلته دائنا. وذللك بأن تعطيه دينا... و التداين و المداينة: دفع الدين" ـ الََّيْن اصطعلاحا: "عبارة عن كل معاملة كان أحد العوضين فيها نقدا، والآخر في الذمة نسيئة. فإن العين عند

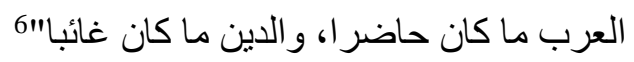
وبعد تعريف هذين المتضايفين يمكن القول بأن توثيق الديون: عبارة عن مجمو عة من البيّنّات، والضمانات التي

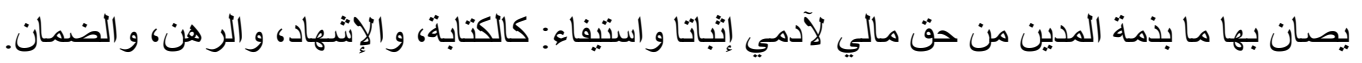
المبحث الأول في المقاصد المالية، والاقتصادية للتوثيق. أولا: المقاصد المالية.

\section{تعريف المال لغة، واصطلاحا}

المال لغة: معروف. و هو ما ملكته من جميع الأشياء. وووردت لفظة المال في القرآن الكريم أكثر من ثمانين مرة: مفردة، وجمعا. ونكرة، ومعرفة مضافة تارة لله عز وجل، وتارة للمتصرف فيه، وتارة غير مضافة مثل قوله تعالى:

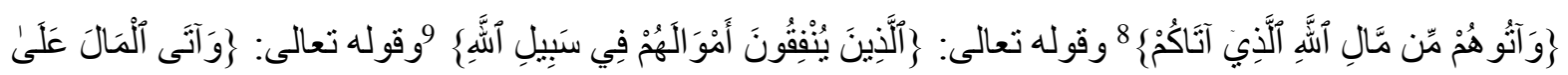

المال في عرف الشرع: " ما بقدره يكون قدر إقامة نظام معاش أفراد الناس في تناول الضروريات و الحاجيات و التحسينيَّات بحسب مبلغ حضارتهم حاصلاً بكدح" 11

3 الصحاح تاج اللغة وصحاح العربية لإسماعيل بن حماد الجوهري. تحقيق أحمد عبد الغفور عطار. ذار الكتب العلمية

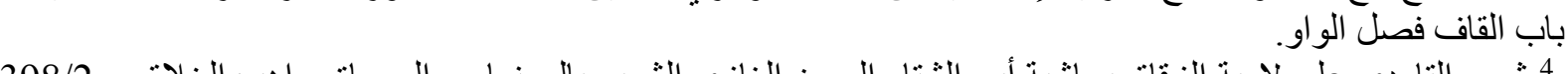
4 شرح التاودي على لامية الزقاق بحاثية أبي الثتاء الحسن الغازي الثهير بالصنهاجي المسماة مواهب الخلاق. ج398/2 ـ المكتبة الأز هرية للتراث لاث. 5 مفردات الفاظ القر آن للر اغب.

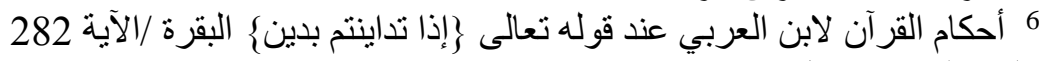

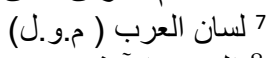
8 النور ـ الآية 33 9البقرة الآية 262 الالبقرة 177 الآية 17 البرة 11 التحرير و التتوير تسير قوله تعالى: \}و لا تاكلو ا أمو الكم بينك بالباطل) سورة القرة/ الآية 188 
الهجلة الدولية لنشر البحوث والدراسات

International Journal of Research and Studies Publishing
المجلد الثاني - الإصدار التاسع عشر تأريخ الإصدار: 20 مايو 2021م

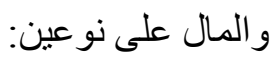

النوع الأول: المال العام. وله رو افده عند الدولة، وله نظامه في جمعه، و إنفاقه.

النوع الثاني: المال الخاص، و هو ما يكتسبه الأشخاص من وجوه الاكتساب، والتملك، و هو الذي سبق تعريفه، وهو المقصود هنا أساسا، ويدخل فيه الثركات، و المؤسسات المالية.

وحفظ المال مقصد ضروري، وحفظه من جهتين:

الجهة الأولى: بتوفير الثروة من مواردها المتعددة الطيبة، بحيث تتم بها الكفاية للأمة في قيام شؤونها كلها الضرورية، و الحاجية، و الكمالية، ومتمماتها. وقد حظ الإسلام على التكسب، و السعي في طلبه لمشي في مناكب الأرض، فقال

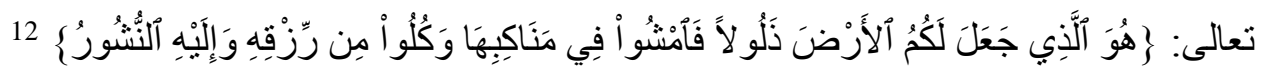
و الثروة: "ما ينتفع به الناس آحادا، وجماعات في جلب نافع، أو دفع ضار في مختلف الأحو ال، والأزمان، و الدو اعي انتفاع مباشرةٍ، أو واسطة. و المال لا يكون ثروة إلا إذا انتظمت له مقوماته من ذلك:

1. أن يكون ممكنا ادخاره: لأن الثيء الذي يسرع إليه الفساد لا يجده صاحبه عند دعاء الحاجة إليه. 2. أن يكون مرغوبا في تحصيله. وذلك فرع عن كثرة النفع به. وذللك بحسب مو اقع الناس

من قرى، وبو ادي، وحو اضر. كالثروة الحيو انية، و النباتية، و المعدنية، و الثروة التي يطلق عليها اليوم "الثروة الا مادية" من نفائس الآثار ، و غير ها.

3. أن يكون قابلا للتداول. أي التعاوض به، و التداول يكون بالفعل أي بنقل ذات الثيء

من حوز أحد إلى حوز آخر، ويكون بالاعتبار مثل عقود الذمم كالسلم، و الحوالة، وبيع البرنامج14، ومصارفة أور اق المصارف.

$$
\begin{aligned}
& \text { 4. أن يكون محدود المقدار. } \\
& \text { 5. أن يكون مكتسبا.15 }
\end{aligned}
$$

12 الملك: الآية 15

13 مقاصد الثريعة الإسلامية ص457

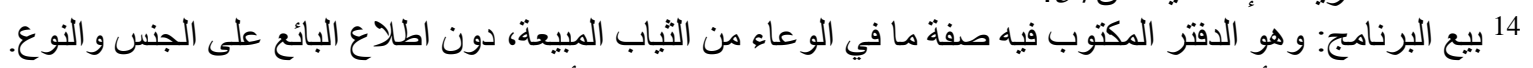

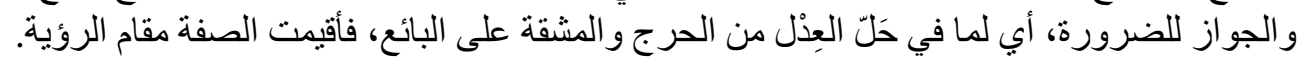
15 نفس المرجع و الصفحة. 


$$
\text { و المكاسب على نو عين: كسب بغير عوض، كسب بعوض. }
$$

أ. الكسب بغير عوض: يشمل الإرث، و التبر عات، و العطايا، وما ليس ملكا لأحد كالحطب.

ب. الكسب بعوض: عوض عن مال كالبيع، و عوض عن عمل كالإجارة، عوض عن جناية كالديات.16 الجهة الثانية: حفظ المال من الضياع، والتلف لأن المال في الإسلام له قيمة، وحرمة. وحفظه من التلف، و الضياع له صور منها: الصورة الأولى: النهي الور اد من الثارع من أكل أموال الناس بالباطل، لتقوية الوازع الديني حتى تتشأ الأمة على طباع شر عية تمنعها من تتاول ما ليس من ملكها، و لا من كسبها الطيب. و التعدي على الأموال سبعة: الحر ابة و الغصب، و الاختلاس، والسرقة، و الخيانة، و الإدلال، و الجهد، و الاقتطاع. 17

الصورة الثانية: التوثيق بمعاييره السابقة. فالتوثيق قانون رباني لحفظ الأموال من الضياع، و التلف، و الإنكار، و النسيان. فإنثبات الحق في ذمة المدين، و التمكن من استخلاصه مقصد شر عي معتبر ينكئ عليه القاضي في الحكم وهو عمل ييسر القضاء، ويوفر الجهد على القضاة. و لأهمية هذه أصبح اليوم منضو تحت خِطة القضاء.

ويعتبر التوثثق في حد ذاته مقصدا شر عيا، ودرجته بحسب العقد الذي صاحبه قال الإمام الثاطبي رحمه الله، وهو

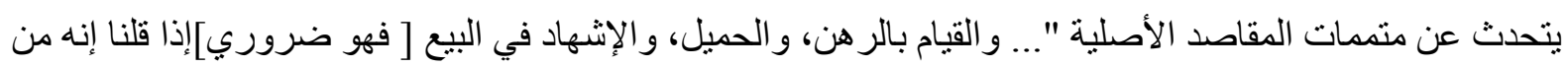

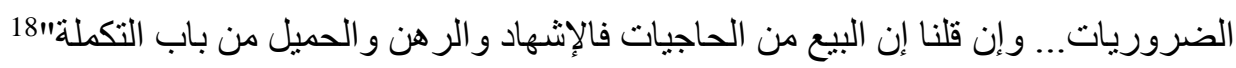

فآية الدين جاءت عقب الحديث عن الإنفاق في سبيل الله، ونظامه، وعقب الحديث عن حلية البيع، وحرمة الربا، وما ينتج عنه من الأضر ار النفسية، و الاقتصادية، و الاجتماعية من أكل أمو ال الناس بالباطل وما ينشأ عنه من ظلم الأقوياء للضعفاء. و عجز الضعفاء عن رفع أغلال الربا التي عليهح.

فكان توثيق الديون معيار ا ضابطا للمال من جهة حفظ الحقوق لأصحابها، ومن جهة تملكه، و اكتسابه، و إنفاقه حيث يكون من وجهاه، وفي حله.

16 القو انين الفقهية لابن جزي كتاب البيوع. بشيء من التصرف.

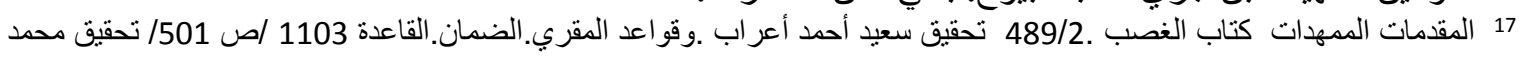
18 الاردبي. 18 افقات كتاب المقاصد: النوع النوع الأول. المسألة الثانية. 
"و المقصد الثر عي في الأموال كلها خمسة: رو اجها، ووضوحها، وحفظها، وثباتها، و العدل فيها". 19 ثانيا المقصد الاقتصادي

قد يعتقد معتقد أن المر اد بتوثيق الديون تضييق جريان العقود المالية، ومحاصرة عملية التداين مما يجعل التعامل منضبطا أساسا بالتقابض عاجلا. إلا ما دعت الضرورة إلبه، والحق خلافه لأن عملية التداين-و هي أحد وجوه التعاوض 20 ــ لها مقاصد عامة منها: الأولى: التيسير على المعسر، وتفريج كربته بالبيع، أو القرض. الثانية: توسيع الثروة، وتتميتها لأن السيولة (أقصد النقود) أحيانا تقل أو تتعدم. الثالثة: الانتهاء عن التعامل بالربا الذي يعرض الثروة للمحق، والإيذان بالحرب من الله.

و التوثيق تسديد، وثرشيد لهذه المقاصد. لأن التوثيق نظام، وقانون رباني يسعى لتيسير التعامل، ورفع الحرج على

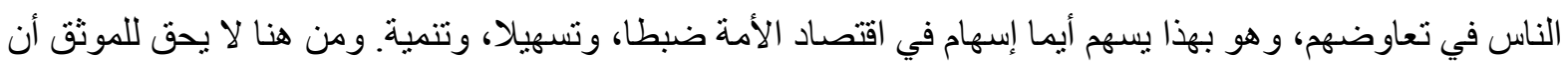
يوثق إلا ما كان من العقود مشرو عا. و أثثير هنا لثناثة مقاصد اقتصادية لتوثيق الدين: المقصد الأول: الاقتصاد في الإففاق.

قصد في الأمر قصدا: توسط، وطلب الأسدَّ، ولم يجاوز الحد، وهو على قصد: أي رشد.21 فالاقتصاد هنا معناه: التوسط في تحصيل الحاجي، و الكمالي من المطعم، والمشرب، و الملبس، والمسكن، والمركب،

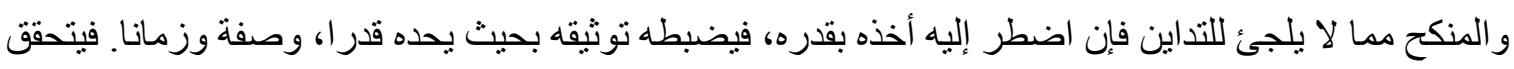
العدل في تحصيله في إبانه مما يقطع على النفوس الضعيفة المماطلة فيه، و إنكاره لهذا قال تعالى: زذلكم أقسط عند

لأن الشريعة الإسلامية لم تأذن في التداين بشروطه المرعية، إلا لرفع الحرج عن هذه الأمة، وتيسير ا عليهم في

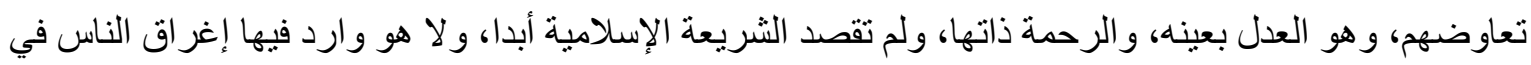
الديون، وشقائهم بها، و التوثيق إنما هو كاثنف لهذه الحقيقة وهو ضابط لها. و المستدين إنما فعل ذلك لرفع ضائقة، أو تحصيل حاجة، أو توسع في تحصيل الكماليات، فحين يعلم المدين أن الدين مضبوط، وأن جز ءا من ماله مثلا مر هون، و هو من الر اثدين سيقتصد في إنفاقه، وسيسلك مسلك الاعتدال، و القو امة فيه.

19 مقاصد الثريعة ص 464 تحقيق ودر اسة محمد الميساوي. دار النفائس الأردن 20 و هي: العين بالعن. الذمة بالذم، و العين العين بالذمة، و والعكس. 


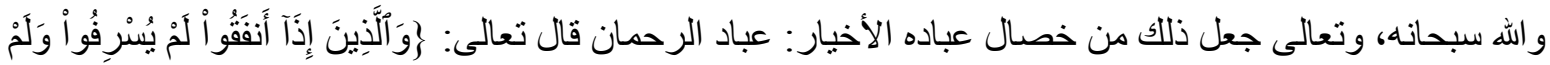

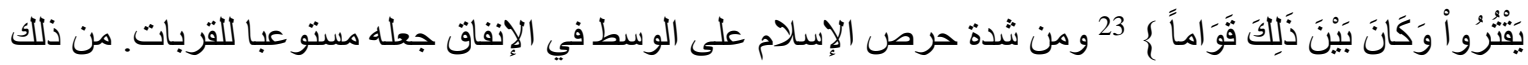

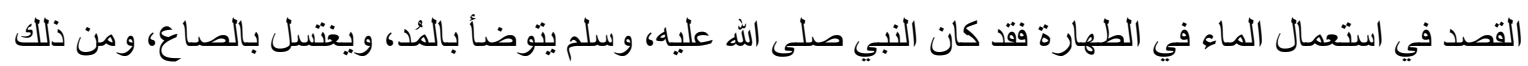
أيضا أنه إذا كان شراء الأضحية يجحف (يوقع في الحاجة) بالنقة على العيال فلا تسن.

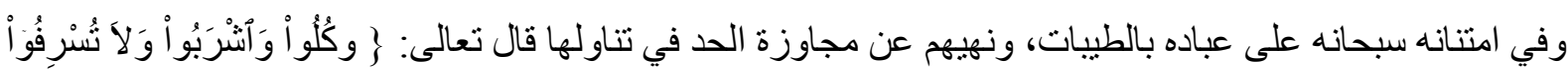

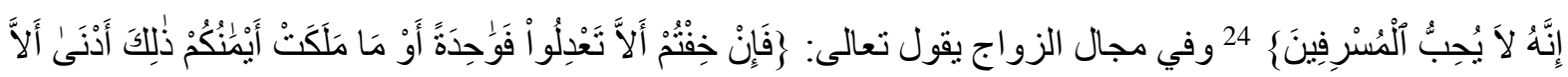

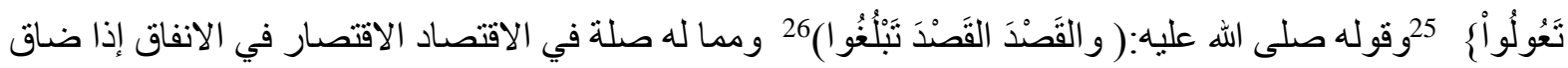

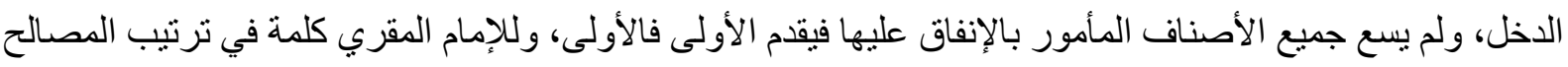

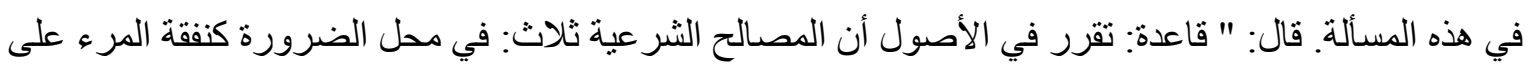

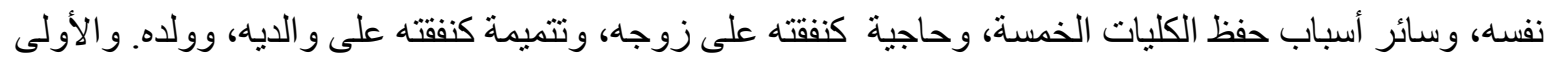
مقدمة على الثانية، و الثانية مقدمة على الثالثة عند التعارض. 27

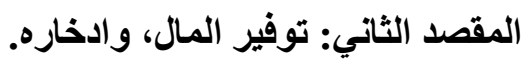

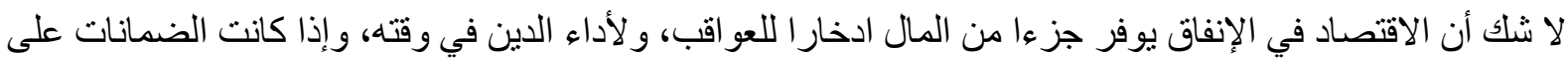

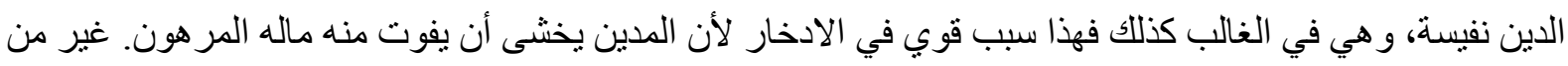
به سفه يدعوه للخمول و الاتكال، فلا يقيم للمال حرمة، و لا للحياة معنى. و على سبيل الثثال: الاقتصاد في استئجار

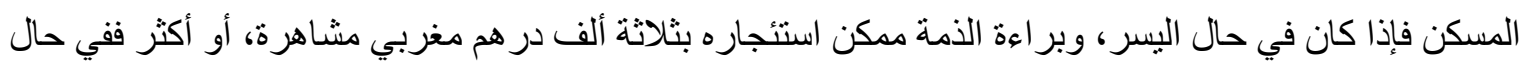

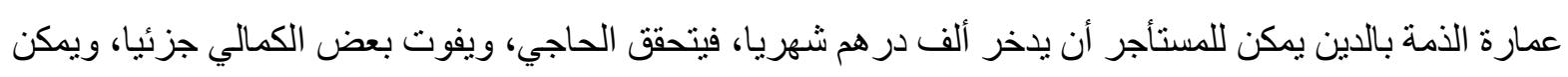
أن يستفاد هذا من قوله نعالى في شأن وجوب السكنى للمطلقات: الوسع، والطاقة. فالمطلّق وجب عليه إسكان المطلقة في المسكن الذي هو فيه و ولا يكلف بتوفير سكن غير بيته فإن

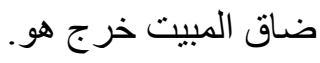

\section{المقصد الثالث: تحقيق تنمية اقتصادية.}

أقصد بالتمية الاقتصادية: توفير الثروة، وتثمير المال بضو ابط الثرع، وآدابه. المفضيان لاستقامة أحو ال المجتمع، واستقر اره المادي، والروحي. 
المجلة الدولية لنشر البحوث والدراسات

International Journal of Research and Studies Publishing

ISSN: 2709-7064
ألمجلد الثاني - الإصدار التاسع عشر

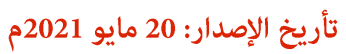

ومقومات هذه التنمية كثيرة، وفي آية نوثيق الديون جملة منها:

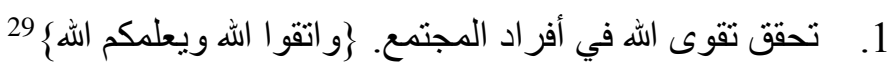

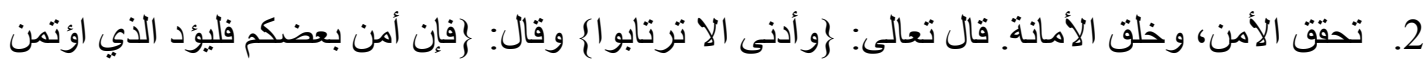

30 أمانته

3. تحقق العدل. \}زلكم أقسط عند الهُ

4. وجود ثروة، ومال للأمة. قال تعالى: \}إلا أن تكون تجارة حاضرة تديرونها بينكم\{ 31 5. توثيق المعاملات المالية، وهو الوسيلة الجامعة لما سبق من المقومات

فحين توثث المعاملات المالية على أصول الثريعة، وقو اعدها، وفروعها، وقيمها: يتحقق العدل، و الأمن و الأمانة بمعية الإيمان و التقوى، وبذلك تتيسر المعاملات، و المعاوضات بين أفر اد المجتمع، نقدا، ودَينا، فيأمن الناس على أمو الهم،

فيتوسع قطاع التبادل، وتتشط العملية التجارية، وتحصل السيولة لدى المؤسسات المالية، وتتهض الأمة تجاريا، وصناعيا، وتكنلوجيا، فتكثر فرض العمل، وتقل البطالة. لأن التداين كما يكون للعسر، ورفع الحرج، يكون للتنمية

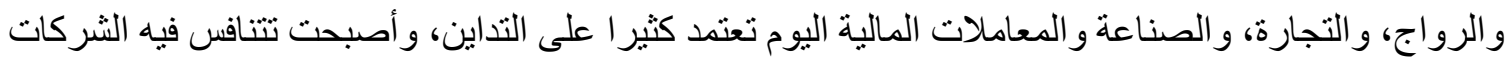
التجارية، والمؤسسات المالية. "و التداين من أعظم أسباب رواج المعاملات لأنّ المقتدر على تتمية المال قد يعوزه المال فيضطرّ إلى التداين ليظهر مو اهبه في التجارة أو الصناعة أو الزراعة، و لأنّ المترفّه قد ينضب المال من بين يديه وله قِبل به بعد حين، فإذا لم يتداين اختلّ نظام ماله، فشرّع الله تعالى للناس بَقاء التداين المتعارف بينهم كيلا يظنّّوا أنّ تحريم الرباو الرجوع بالمتعاملين إلى رؤوس أمو الهم إبطال للتداين كلّه. و أفاد ذللك التشريعَ بوضعه في تشريع آخر

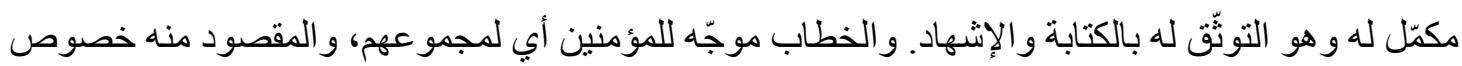

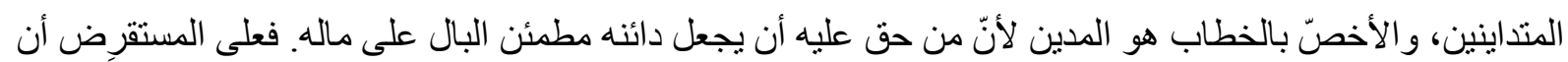
بطلب الكتابة و إن لم بيسألها الدائن."32 - 2 المبحث الثاني: في المقصد الاجتماعي. المجتمع المسلم مجتمع مرصوص له مقومات، و أصول عديدة ضابطة، وبانية منها القانونية، و الاقتصادية، و السياسية،

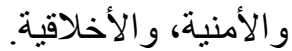

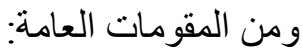

292

البقرة الآية 283 الآية

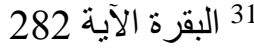

32 التحرير والتتوير تفسير آية الدين. 
المجلة الدولية لنشر البحوث والدراسات

International Journal of Research and Studies Publishing
ألمجلد الثاني - الإصدار التاسع عشر

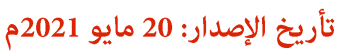

1. انتظام أفر اد المجتمع في سمط تآلفي عقدي، وعملي، وروحي: مثل الأخوة الإسلامية،

$$
\text { و غير ها من الروابط التي أذنت الثريعة الإسلامية في بنائها. }
$$

2. قيامه على نظام سياسي: قيام المجتع على نظام القيادة، والولاية التي أساسها الثورى، والبيعة،

و الذي ينتظم مجمو عة من الخِطط، و الو لايات، وون جملتها خطة القضاء، وما يتفرع عنها. وقيام المجتمع على نظام سياسي شر عي يقصد إلى تحقيق أمور كثيرة ضابطة لمسار المجتمع مثل: اتحاد الأمة، والعدل، و المساو اة، والتعاون، و المو اساة، والحرية، وحماية المجتمع من جميع الآفات، وتوفير الثروة، و المال، و غير ذلك.

فهذان مقومان عامان لضبط سير المجنمع

لذلك كانت هذه " النظم ترعوي إلى فنين أصليين:

الفن الأول: فن القو انين الضابطة لتصرفات الناس في معاملاتهم.

الفن الثاني: فن القو انين التي بهار رعاية الأمة في مر ابع الكمال، والذود عنها أسباب الاختلال." 33

و الأنموذج المجتمعي هو ما أرسى أصوله النبي صلى الله عليه وسلم، و أسس قو اعده فور وصوله للمدينة المنورة من

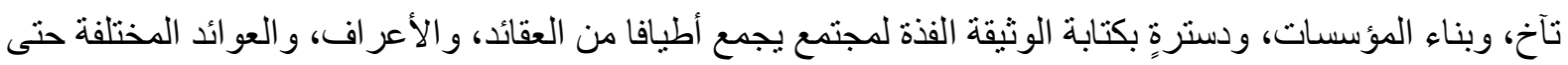
بين المسلمين أنفسهم من المهاجرين، و الأنصار ، و الأنصار أيضا فيما بينهم في أحيائهم.

أساس هذا المجتمع التآلف، و التناصر ، و التعاون، والأمن... لا شيء يعلو فيه على القيم الإنسانية، و الأخلاق الفاضلة التي بعث النبي صلى الله عليه وسلم لإكمالها. فمكارم الأخلاق هي روح الأعمال، وثمار ها، و أساس تماسك المجتمع، ففي الحديث الثريف يقول الرسول صلى الله عليه وسلم (بعثت لأتمم حسن الأخلاق) 34.

و الإنسان بفطرته مجبول على حب الثروة، و اكتساب المال. وتحقيق ذلك متوقف على التعامل مع أفر اد المجتمع، وهذا يحتاج إلى تأمين المجتمع من ضياع حقوقه المالية، سواء كانت المعاوضات عينية، أم دينا في الذمة. ناشئا عن بيع، أو

$$
\text { قرض، أو سو اهما. }
$$

و المقصد الاجتماعي من نوثيق الديون هو حفظ النظام الاجتماعي الإسلامي ويتضمن مجمو عة من المقاصد منها: حفظ النفوس، و الحقوق، و القيم.

$$
\begin{aligned}
& 33 \text { أصول النظام الاجتماعي في الإسلام لابن عاشور ص } 122 \\
& 34 \text { الموطأ باب ما جاء في حسن الخلق في الإسلاع }
\end{aligned}
$$


المجلة الدولية لنشر البحوث والدراسات

International Journal of Research and Studies Publishing
المجلد الثاني - الإصدار التاسع عشر تأريخ الإصدار: 20 مايو 2021م

ISSN: 2709-7064

وحاولت أن أتعرض في هذا المقصد الاجتماعي لما دلت عليه آية الدين من المقاصد نطقا، أو فهما في قوله تعالى: \} ذلكم أقسط عند الله، و أقوم للشهادة، و أدنى أن لا ترنابو إئ 35 منها:

المقصد الأول: تحقيق العدل، و المساو اة [العدالة الاجتماعية]

المقصد الثاني: تثبيت الحق، وتمكين صاحبه منه

المقصد الثالث: الثقة، ونفي الريية.

المقصد الر ابع: التعاون، و المواساة.

المقصد الخامس: حفظ النفوس.

المقصد الأول: العدل، والمساوة.

هذا المقصد دل عليه قوله تعالى في آية الدين \}ذلكم أقسط عند الله\{ كون التوثيق بأنو اعه أقسط عند الله "لأنه أحفظ للحق"، و"لأنه إذا كان مكتوباً كان إلى اليقين و الصدق أقرب، و عن الجهل و الكذب أبعد، فكان أعدل عند الله"36و لأن

القضاة بيتنيرون بالحجة، لتعيين الحق، وتمكين مستحقه منه، وتعبين الحق من أهم مقاصد الثريعة

و القسط: هو العدل: و هو "تمكين صاحب الحق بحقه بيده، أو يد نائبه، وتعيينه له قولا، أو فعلا"38. ومن وسائل ذلك كله المثبتة، و الممكّنة من استفائه عند طلبه: نوثيقه. و العدل ظاهر في الحكم بين الناس، عند التناز ع قال تعالى: (روَإِذَا

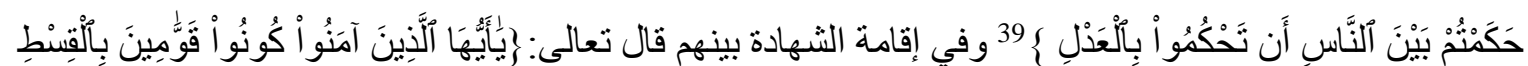

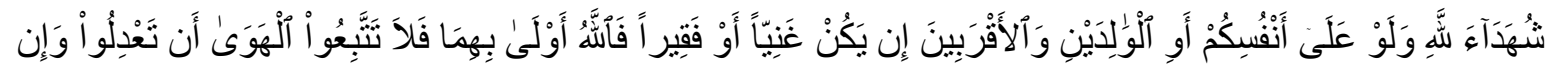

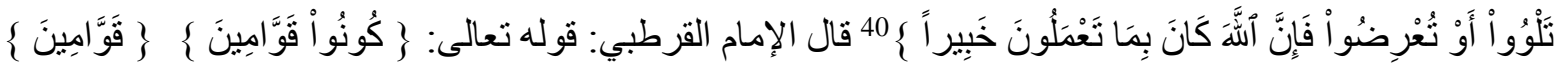

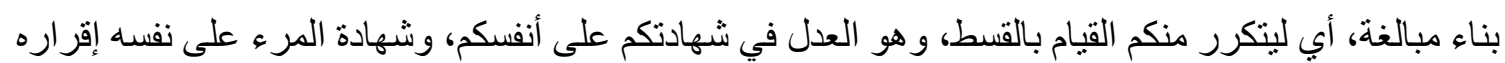
بالحقوق عليها. ثم ذكر الو الدين لوجوب برِّها وعِظم قدر هما، ثم ثنّى بالأقربين إذ هم مظنة المودّة و التعصب فكان الأجنبي من الناس أحرى أن يقام عليه بالقسط ويشهد عليه، فجاء الكلام في السورة في حفظ حقوق الخلق في

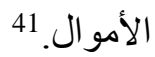
37 خصص له الشيخ الطاهر بن عاشور فصلا في مقاصد الشريعة. 38 أصول النظام الاجتماعي لابن عاشور ص 386 39 النساء الآية 58 135 40 النساء الآبية

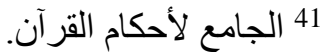


المساواة: المعادلة، المعتبرة بالذات، أو الكيفية، و استعملت بمعنى العدل. وتطلق على فاعلين فصاعدا، و على اعتدال

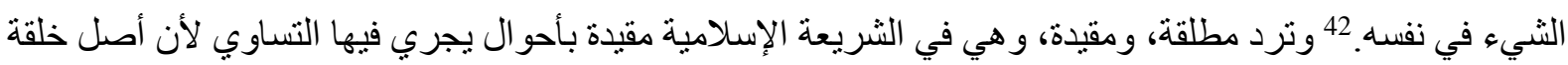
البشر جاءت على التفاوت في المو اهب، والأخلاق 43 ونوثيق الدين بمكن للتعامل بين الفقر اء، و الأغنياء، و الضعفاء، والأقوياء، ويحقق تكافؤ الفرص، جاءع

\section{المقصد الثاني: تثبيت الدق، وتمكين صاحبه منه.}

يكفي أن تكون إحدى وسائل الإثبات ضامنة للحق، مطمئنة للمتداينين لكن كلما تعاضدت ازداد الحق ثباتا وتمكنا. لهذا قال تعالى في آية الدين: \} و أقوم للشهادة) أي الكتابة أثنبت للشهادة لتعاضدهما لما قد يكون من النسيان من الثهود. لهذا أجمع فقهاء الشريعة، والقانون على هذه الوسائل كلها

\section{المقصد الثالث: الثقة، ونفي الربية.}

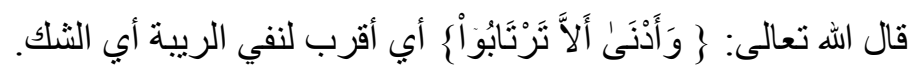

الثقة: قال الر اغب: "وثقت به أثِق سكنت إليه، واعتمدت عليه" 44 وقال الجرجاني: "هي التي يعتمد عليها في الأقوال، والأفعال"45

و النص القر آني يفيد بمفهومه أن التداين بدون توثيق، وضمانات قد يؤدي إلى الثك، و الريبة، و الخوف على ضياع الحقوق المالية والآية ظاهرة في كون نفي الثك، و الارتياب مطلب اجتماعي، وينبني عليه أن الثقة خلق رفيع، به نمنلاك مسار جميع العلاقات الاجتماعية، وهو صمام الأمان لكل تعامل مالي، و غيرها.

ووسائل التوثيق، ومعاييره كلها من أهم ما يزرع الثقة، والطمأنينة مما يفتح باب التعامل بالتداين بين أفر اد المجتمع، و المؤسسات، المالية و غير ها باعتباره نظاما شر عيا محكما.

ويجب أن تكون الثقة منبثة منبادلة بين أفر اد المجتمع، فيأمن الدائن على حقه بأن يستوفيه من المدين عند حلوله، وبقدره، ويأمن المدين على ما قدمه من الضمانات فيستردها حينما يقضي ما عليه قال تعالى:

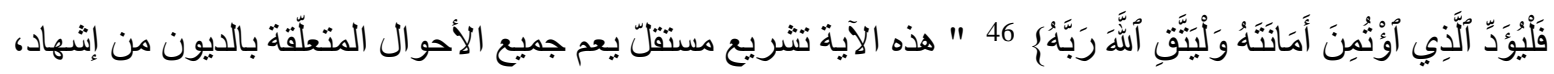

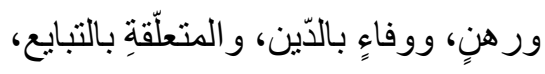

$$
\begin{aligned}
& 42 \text { مفردات الفاظ القرآن الكريم للر اغب بتصرف. } \\
& 43 \text { أصول النظام الاجتماع لابن الكريم لانشور. } \\
& 44 \text { مفردات الفاظ القر آن الكريم. لإني عات } \\
& 45 \text { التعريفات مفرات } \\
& 46 \text { البقرة الآية } 283
\end{aligned}
$$


ولهذه النكتة أبهم المؤتمنون بكلمة \} بعض \{ ليشمَل الائتمان من كلا الجانبين الذي من قبل ربّ الدين، و الذي من قبل

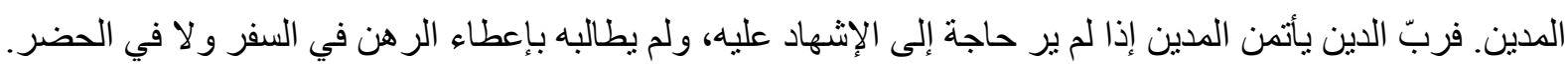
و المدين باتَمن الدائنَ إذا ستلَّم له رهناً أغلى ثمناً بكثير من قيمة الدين المرتهَنْ فيه، والغالب أنّ الرهان تكون أوْفَرَ قيمة

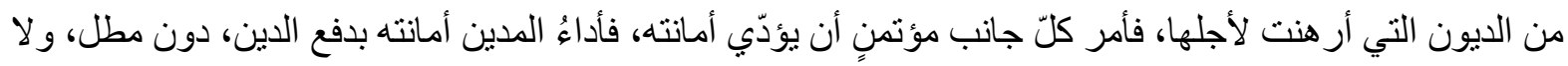

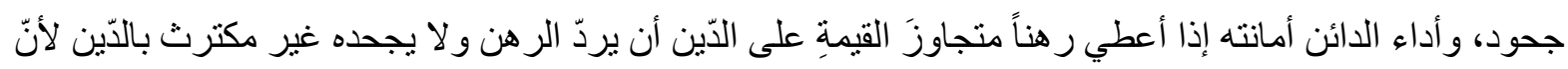

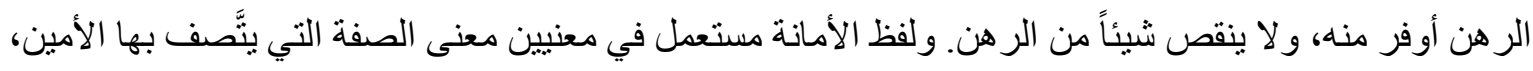

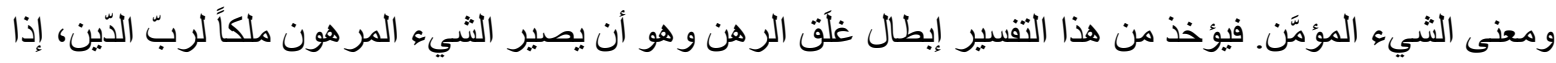

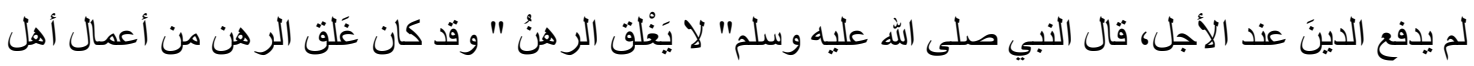

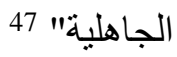

و الثقة يمكن تصريفها في هذا السياق إلى ثلاثة أنواع:

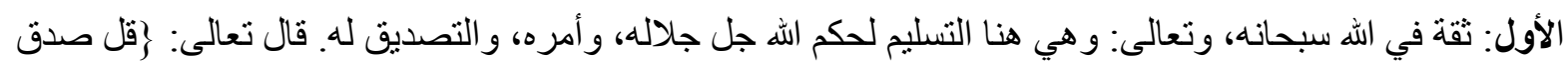

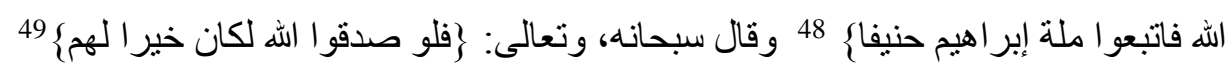

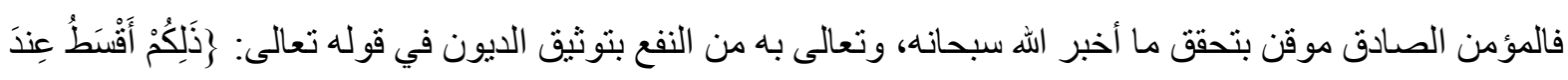

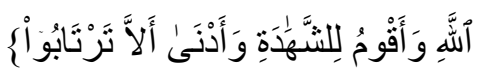

الثاني: ثقة بالنفس05. أعني اعتقاد أن التعامل بالتداين سلوك يُنتج ذوي الإيمان القوي الناظرين بالإيجابية لفعالية

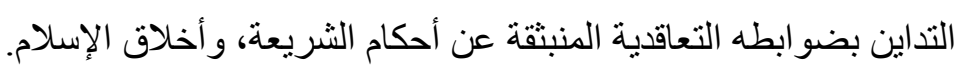

الثالث: ثقة اجتماعية: التفاعل الإيجابي بين أفراد المجتمع شاملة للجانب المالي، والسياسي، وقيم التعارف، و التعامل

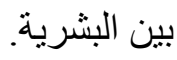

و هذه الثلاثة من الثقات يفضي بعضها لبعض مما يقوي ثقة التعامل بالدين، وينفي الريبة، ويقطع أسباب الخلاف،

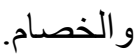

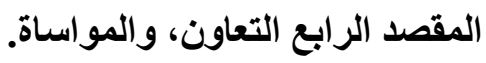
حين يتحقق العدل، و المساو اة تزرع الثقة، فينتج عن ذلك كله خلق المواساة. و التعاون.

أن التحرير، و التنوير.

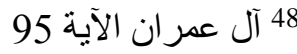

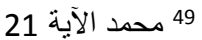
50 كثر الحديث في الآونة الأخيرة عن الثنة بالنفس، و'التتمية الذاتية' ومن الكتب في هذا الموضوع كتاب: الثقة،

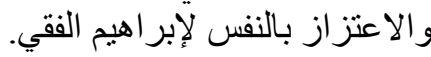


المجلة الدولية لنشر البحوث والدراسات

International Journal of Research and Studies Publishing
المجلد الثاني - الإصدار التاسع عشر تأريخ الإصدار: 20 مايو 2021م

$$
\text { و المواساة: كفاية حاجة محتاج الثيء مما به صلاح الحال51 }
$$

و هي خلق فطري، ونظام إسلامي عام لما يقدم من الخدمات المالية، و غير ها على جهة التبرع، أو التعاوض، و النصوص من القر آن الكريم، والسنة النبوية كثيرة في هذا الباب. وكثير من حاجيات أفر اد المجتمع ثُقضى بالتداين

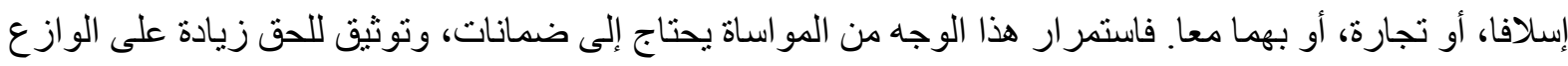
الإيماني.

وتحقق المو اساة حين يؤمن كل فرد بأنه خلية من نسيج مجتمعه. لهذا قال رسول الهه صلى الهه عليه، وسلم:( ترى المؤمنين في تر احمهم، ونو ادهم، وتعاطفهم كمثل الجسد إذا اشتكى عضو ا تداعى له سائر جسده بالسهر ، و الحمى) 52, الحديث يثير للتداعي الإيجابي أي تفاعل جميع أعضاء الجسد مقاومة للاءاء، فكان من اللائق بالمجتمع ألاًّ يناقض هذه الحقيقة التي لا تتخلف في الجسد، وإن كانت تسخيرية في الجسد، واختيارية في التعامل بين أفراد المجتمع. المقصد الخامس: حفظ النفوس. توثيق الديون حافظ للنفوس من الاعتداء عليها سو اء كان الاعتداء نفسيا، أم جسديا، لما قد ينشأ من عدم التوثيق، من النتاجر ، والاختلاف بسبب النسيان، أو النكران، أو المماطلة. والأمن على النفوس مقصد شر عي ضروري.

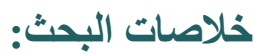

مر اعاة هذه المقاصد المالية، والاجتماعية لتوثيق الديون لها أهمية عظيمة، وفو ائد كثيرة منها: 1. حفظ الحقوق المالية من الضياع، و التلاعب، لأن توثيقها يضمن ذللك لها سواء على مستوى الأفراد أم على

$$
\text { مستوى المؤسسات المالية. }
$$

2. حفظ القيم، و الأخلاق في المجتمع كالأخوة، و المحبة، و الثقة... 3. تحقيق العدالة، و الحماية الاجتماعية بتداول المال بين أفراد المجتمع. 4. الانضباط في التعامل بالتداين بأن لا يكون إلا لحاجة ملحة و الحمد لله رب العالمين. وصل اللهم على سيدنا محمد، و على آله وصحبه، وتابعيهم بإحسان

$$
\begin{aligned}
& 51 \text { أصول النظام الاجتماعي للشيخ الطاهر بن عانشور ص } 137 \\
& 52 \text { صحيح البخاري رقم الحديث } 6011
\end{aligned}
$$


المجلة الدولية لنشر البحوث والدراسات

International Journal of Research and Studies Publishing
|مجلد الثاني - الإصدار التاسع عشر تأريخ الإصدار: 20 - 20 مايو 2021م

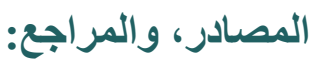

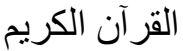

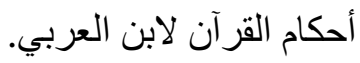

أصول النظام الاجتماعي للثيخ الطاهر بن عانور .

التحرير، و التتوير لابن عاثور [ت 1393ه] الدار التونسية للنشر. الدار الجماهيرية للنشر، والتوزيع، و الإعلان.

التعريفات للجرجاني دار الكتب العلمية بيروت.

الجامع أحكام القرآن الكريم للإمام القرطبي [ت 6710] إعداد المكتب الثقافي للنشر دار الفكر للطباعة والنشر،

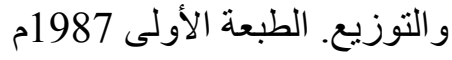

شرح التاودي على لامية الزقاق بحاثية أبي الثناء الحسن الغازي الثهير بالصنهاجي المسماة مواهب الخلاق ج398/2 ـ المكتبة الأزهرية للتراث.

صحيح البخاري بشرح فتح الباري. حقق أصولها، وأجاز ها الثنخ عبد العزيز بن باز. دار الفكر الصحاح تاج اللغة وصحاح العربية لإسماعيل بن حماد الجوهري. تحقيق أحمد عبد الغفور عطار. ذار الكتب العلمية. • - 398/2 ـ المكتبة الأزهرية للتراث. القو اعد للمقري [ ت759ه] تحقيق محمد الدردابي. دار الأمان الرباط 2012 القو انين الفقهية لابن جزي [ت 741هـ] دار المعرفة موطأ الإمام مالك بن أنس برواية يحيى بن يحي الليثي. منشورات المجلس العلمي الأعلى. مطبعة النجاح الجديدة الدار البيضاء. ط الأولى 1443ه المصباح المنير

مفردات الفاظ القر آن الكريم للر اغب الأصفهاني [ت425ه] تحقيق صفوان عدنان داوودي. دار القلم دمشق، دار

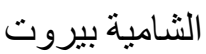

مفاتيح الغيب للرازي، دار إحياء التراث العربي - بيروت الطبعة: الثالثة - 1420 هـ مقاصد الثريعة ص 464 تحقيق ودر اسة محمد الميساوي. دار النفائس الأردن المو افقات كتاب المقاصد المسالة الر ابعة. تحقيق عبد الله دراز 14/2 طوزارة الأوقاف السعودية.

Doi: doi.org/10.52133/ijrsp.v2.19.10 